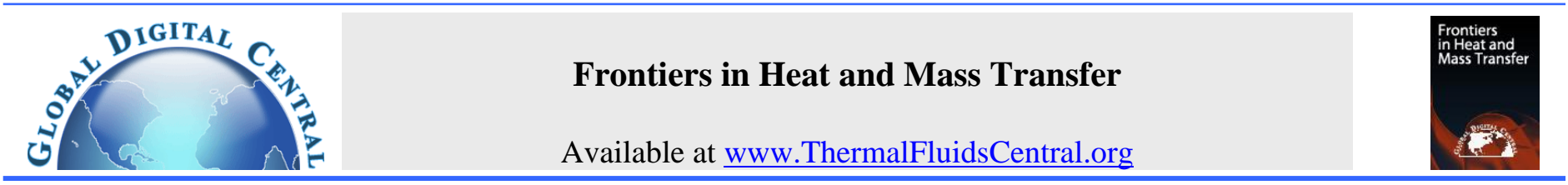

\title{
MHD FLOW IN A CIRCULAR HORIZONTAL PIPE UNDER HEAT SOURCE/SINK WITH SUCTION/INJECTION ON WALL
}

\author{
G. Nagaraju ${ }^{\mathrm{a}, *}$, Mahesh Garvandha ${ }^{\mathrm{b}}$, J.V. Ramana Murthy ${ }^{\mathrm{c}}$ \\ ${ }^{a}$ Center for Research and Strategic Studies, Lebanese French University, Kurdistan Region Erbil, Iraq \\ ${ }^{\mathrm{b}}$ Research Scholar, Dept. of Mathematics, GITAM Deemed to be University, Hyderabad, India. \\ ${ }^{\mathrm{c}}$ Department of Mathematics, NIT Warangal, Telangana, India
}

\begin{abstract}
This paper analyzes a hypothesis of the 2-dimensional thermal transport behavior of Newtonian axisymmetric, viscous heating flow in a horizontal pipe. The flow is subjected to an externally applied uniform suction across the pipe wall in the polar direction, a constant magnetic field perpendicular to the wall and a uniform heat source/sink on the surface of the cylinder. The thermal boundary condition is imposed as a uniform heat flux. The Velocity fields are expressed in terms of stream function and the solution is obtained using the homotopy analysis method (HAM). Graphs are designed to analyze the significant effect on temperature and velocity fields of different flow and geometric parameters. Streamline, isotherm and pressure contours are also presented. It is observed that the temperature distribution increases with an increase in Prandtl number, whereas it decreases with an increase in Eckert number (viscous dissipation effect).
\end{abstract}

Keywords: Magnetohydrodynamics, Circular pipe, HAM, Suction, Heat source/sink, Nusselt number, Stokes operator, Stream function.

\section{INTRODUCTION}

Newtonian channels or pipes are abundant in industrial applications, including cooling systems, petrochemical transport (natural gas and heavy oil) and biotechnology. The aforementioned flows are often accompanied by heat transport with a classic example being the expulsion of thermal energy from the hydronic space heating framework (Rhee et al., 2011) by spreading water in the heater and then by funnels to the applicable areas. Other heat transport systems in the viscous tube flow are heat exchangers, space heating management (Walker et al., 2013), and solar collector arrangements ( Hussein et al., 1999).

In recent past, engineers have also investigated the modification of viscous flows via wall permeability of the pipe/channel. Injecting or removing fluid through pores is a robust flow control mechanism (Tien (1975)). The present technology has great potential in engineering areas like rocket and cooling technology, and food protection. Mathematical modelling about flows in channel or tubes with wall suction has therefore stimulated some interest in the research community. Berman (1953) first introduced a progression of answer for uniform infusion and/or suction impacts of the Newtonian stream in a penetrable straight channel. Bansal (1967) enlarged this work for steady viscous fluid through a permeable pipe. He acquired an investigative articulation for velocity and skin friction affected by a suction parameter on the pressure gradient. In addition, (Terril, 1982, 1983), detailed a scientific response for moving through a horizontal pipe with consistent suction/infusion at the wall. Tsangaris

*Corresponding author. Email: naganitw@gmail.com and Kondaxakis (2007) checked the time-dependent viscous flow in a suction porous pipe. They introduced a correct answer as time-differing suction on the porous wall. Cox and Hill (2011) have examined the viscous liquid flow crosswise over carbon nanotubes went with Navier slip condition at wall. Ramana Murthy et al., (2012) have examined micropolar flow created by a permeable vertical pipe displaying rotatory motions.

Magentohydrodynamics (MHD) is also an active area of modern engineering sciences and involves the interaction of magnetic forces and electrical fluids. MHD tube flows occur in ionized accelerators, flow restriction in nuclear reactors, generators of energy, processes of manufacturing of liquid metals, levitation of bubbles, etc. (Anwar et al., 2011). MHD flows with wall effects of absorption/injection have attracted considerable attention. In a channel affected by a Lorenz force, Terrill and Shrestha (1963) showed a systematic examination of laminar flow. They found that surface contact upgrades with an expansion in magnetic parameter. Attia (2003) investigated the time dependent non-Newtonian flow across a tube with pressure gradient in flow direction. Attia and Ahmed (2005) computed solutions for unsteady magnetic viscoplastic flow in a straight tube. They found that skin friction is hoisted because of an ascent in molecule stage thickness. Moustafa (2006) has considered the partial viscoelastic fluid in a roundabout cylinder. He introduced velocity arrangements as far as Fox's H-work. Two-dimensional double diffusive magnetized Non-newtonian fluid through a stretching sheet with radiation, hear source and chemical reaction was investigated by Nagaraju et al., (2016). Amanulla et al., (2018) examined a theoretical study of Mhd free convection flow of a Williamson fluid through vertical cylinder with momentum and thermal slips. They observe that increasing thermal slip parameter, decelerates temperature.

The above studies have ignored the effects of dissipation that in many applications can exert a large influence. The effect of dissipation also depends heavily on if the tube is hot or cool (Davaa et al., (2004)). Furthermore it has been established that viscous heating has a key role 
in liquids with small thermal conductivity and greater viscosity. Historically Brinkman (1951) initiated studies of viscous heating. An important study about viscous dissipation was communicated by Gebhart (1962), in occurrence of boundary layer flows. Ou and Cheng (1973) examined the impact of viscous heating at the passage for a round pipe with consistent heat flux. Aydin (2005) has presented closed-form solutions for viscous heating effects in fully developed heat transfer pipe flow. Anwar et al., (2009) computed electro-thermal numerical solutions for nonlinear MHD transient flow and energy transport in Darcian channel through Ohmic dissipation (Joule heating). Other motivating and current investigations into pipe thermofluid dynamics have been communicated in (Nabil et al., (2002); Ahmet et al., (2003); Rached et al., (2005); Srinivas et al., (2014); Nagaraju et al.,(2017) ).

In the present article, we inspect hypothetically the 2D heat transport responses in a horizontal pipe under related magnetic field, constant suction and heat source/sink forced at surface of the tube. With the Homotopy Investigation Technique (HAM) (Lio (2003)), the transformed over, dimensionless boundary value problem (BVP) is solved. The present work sums up past examinations by considering heat source impacts and moreover gives a strong analytical benchmark against which numerical arrangements might be contrasted and an examination is relevant with MHD vitality structures.

\section{MATHEMATICAL HYDROMAGNETIC HEAT TRANSFER MODEL}

Consider an electrically leading Newtonian (viscous) liquid in an infinitely long cylinder of radius $a$, is exposed to a remotely related uniform suction over the divider the typical way as appeared in Fig. 1. As the tube is of semi infinite length, the flow is considered to be fully developed. This flow is exposed to an outwardly applied perpendicular suction across the wall and a constant magnetic force field $B_{0}$ in polar direction. The number of magnets is small enough to neglect the effects of the magnetic field being induced. The primitive equations for viscous flow (Bird et al., (1960)) are:

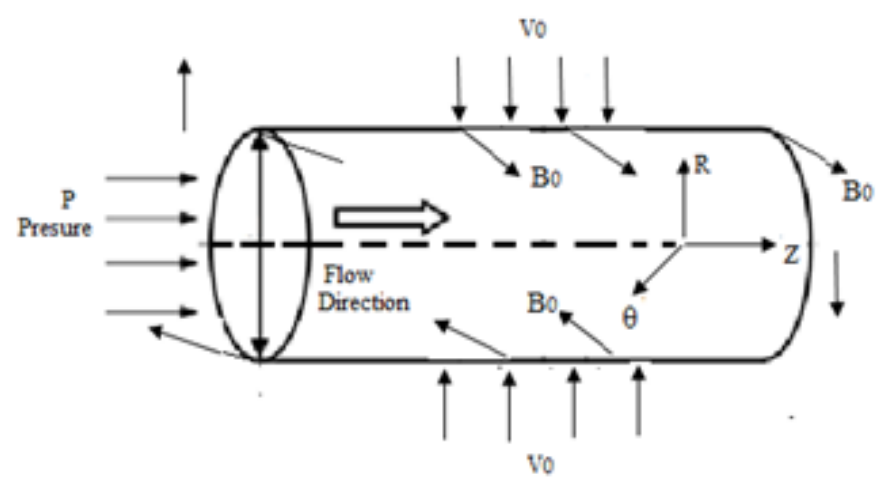

Fig. 1 Schematic diagram

$$
\begin{gathered}
\frac{\partial U}{\partial R}+\frac{U}{R}+\frac{\partial W}{\partial Z}=0 \\
\rho\left(U \frac{\partial U}{\partial R}+W \frac{\partial W}{\partial Z}\right)=-\frac{\partial P}{\partial R}-\mu \frac{\partial}{\partial Z}\left(\frac{\partial U}{\partial Z}+\frac{\partial W}{\partial Z}\right)-\sigma B_{0}^{2} U \\
\rho\left(U \frac{\partial W}{\partial R}+W \frac{\partial W}{\partial Z}\right)=-\frac{\partial P}{\partial Z}+\frac{\mu}{R} \frac{\partial}{\partial R}\left(R\left(\frac{\partial U}{\partial Z}-\frac{\partial W}{\partial R}\right)\right)-\sigma B_{0}^{2} W
\end{gathered}
$$

$$
\begin{array}{r}
\rho c_{p}\left(U \frac{\partial T}{\partial R}+W \frac{\partial T}{\partial Z}\right)=k_{T}\left(\frac{\partial^{2} T}{\partial R^{2}}+\frac{1}{R} \frac{\partial T}{\partial R}+\frac{\partial^{2} T}{\partial Z^{2}}\right) \\
+\mu\left\{2\left[\left(\frac{\partial U}{\partial R}\right)^{2}+\left(\frac{\partial W}{\partial Z}\right)^{2}+\left(\frac{U}{R}\right)^{2}\right]+\left(\frac{\partial U}{\partial Z}+\frac{\partial W}{\partial R}\right)^{2}\right\} \\
+Q_{0} T
\end{array}
$$

The boundary conditions on the axis are obtained by taking the flow to be symmetrical, so that

At $R=0, \frac{\partial W}{\partial R}=U=\frac{\partial T}{\partial R}=0$

At $R=a, W=0, U=v_{0}$, and $K_{T} \frac{\partial T}{\partial R}=q_{w}$

To continue, we present the accompanying transformations: (Nagaraju et al., (2018))

$$
u=\frac{U}{v_{0}}, w=\frac{W}{v_{0}}, r=\frac{R}{a}, p=\frac{P}{\rho v_{0}^{2}}, z=\frac{Z}{a}, \theta=\frac{T}{T_{1}}
$$

Substituting relations Eq. (5) into Eqs. (1) -(4), following dimensionless system of equations, emerge:

$$
\frac{\partial u}{\partial r}+\frac{u}{r}+\frac{\partial w}{\partial z}=0
$$

$$
\begin{gathered}
\operatorname{Re}\left(u \frac{\partial u}{\partial r}+w \frac{\partial u}{\partial z}\right)=-\operatorname{Re} \frac{\partial p}{\partial r}-\frac{\partial}{\partial z}\left(\frac{\partial u}{\partial z}-\frac{\partial w}{\partial r}\right)-M^{2} u \\
\operatorname{Re}\left(u \frac{\partial w}{\partial r}+w \frac{\partial w}{\partial z}\right)=-\operatorname{Re} \frac{\partial p}{\partial z}+\frac{1}{r} \frac{\partial}{\partial r}\left(r\left(\frac{\partial u}{\partial z}-\frac{\partial w}{\partial r}\right)\right)-M^{2} w \\
\operatorname{Re} \operatorname{Pr}\left(u \frac{\partial \theta}{\partial r}+w \frac{\partial \theta}{\partial z}\right)=E c \varphi+\nabla^{2} \theta+Q \operatorname{Pr} \theta
\end{gathered}
$$

where $\varphi=2\left[\left(\frac{\partial u}{\partial r}\right)^{2}+\left(\frac{\partial w}{\partial z}\right)^{2}+\left(\frac{u}{r}\right)^{2}\right]+\left(\frac{\partial u}{\partial z}+\frac{\partial w}{\partial r}\right)^{2}$, $\nabla^{2}=\left(\frac{\partial^{2} \theta}{\partial r^{2}}+\frac{1}{r} \frac{\partial \theta}{\partial r}+\frac{\partial^{2} \theta}{\partial z^{2}}\right), R e=\frac{\sigma v_{0} a}{\mu}, M^{2}=\frac{\rho B_{0}^{2} a^{2}}{\mu}, \operatorname{Pr}=\frac{\mu c_{p}}{k_{T}}$, $E c=\frac{\mu v_{0}^{2}}{k_{T} T_{1}}, Q=\frac{Q_{0} a^{2}}{\mu c_{p}}$

A stream function $\psi$ might be characterized to satisfy the mass conservation Eq. (6):

$$
u=-\frac{1}{r} \frac{\partial \psi}{\partial z}, w=\frac{1}{r} \frac{\partial \psi}{\partial r}
$$

Eliminating the pressure gradient terms from Eq. (7) and Eq. (8), yields:

$$
\begin{aligned}
R e\left(-2 \frac{1}{r^{3}} \frac{\partial \psi}{\partial z} E^{2} \psi+\frac{1}{r^{2}}\right. & \left.\left(\frac{\partial \psi}{\partial z} \frac{\partial E^{2} \psi}{\partial r}-\frac{\partial \psi}{\partial r} \frac{\partial E^{2} \psi}{\partial z}\right)\right) \\
& =-\frac{1}{r} E^{2}\left(E^{2} \psi\right)+\frac{M^{2}}{r} E^{2} \psi
\end{aligned}
$$

where $E^{2}=\frac{\partial^{2}}{\partial r^{2}}-\frac{1}{r} \frac{\partial}{\partial r}+\frac{\partial^{2}}{\partial z^{2}}$

$$
\text { Assume } \psi=(N-z) f(r)(\text { Terril and Shresta (1963)) }
$$

Using Eq. (12) in Eq. (11) we get,

$$
\operatorname{Re}\left(\frac{3 f f^{\prime \prime}}{r^{2}}-\frac{3 f f^{\prime}}{r^{3}}-\frac{f f^{\prime \prime \prime}}{r}+\frac{f^{\prime} f^{\prime \prime}}{r}-\frac{\left(f^{\prime}\right)^{2}}{r^{2}}\right)=D^{2}\left(M^{2}-D^{2}\right) f
$$

where $D^{2}=\frac{d^{2}}{d r^{2}}-\frac{1}{r} \frac{d}{d r}$ is a differential operator.

The corresponding boundary conditions are

$$
\left.\begin{array}{r}
f=D^{2} f=\theta^{\prime}=0 \text { at } r=0, \\
f^{\prime}=0, \quad f=\theta^{\prime}=1, \text { at } r=1 .
\end{array}\right\}
$$




\subsection{Pressure Distribution}

The pressure(p) is the result of Eqs. (7) - (8),

$$
\begin{gathered}
\operatorname{Re} \frac{\partial p}{\partial r}=\operatorname{Re}\left(\frac{f^{2}}{r^{3}}-\frac{f f^{\prime}}{r^{2}}\right)-\frac{\left(D^{2}-M^{2}\right) f}{r} \\
\operatorname{Re} \frac{\partial p}{\partial z}= \\
-\frac{N-z}{r}\left\{\frac{d}{d r}\left(D^{2}-M^{2}\right) f-\operatorname{Re}\left(\frac{f f^{\prime \prime}}{r}-\frac{f f^{\prime}}{r^{2}}-\frac{\left(f^{\prime}\right)^{2}}{r}\right)\right\}
\end{gathered}
$$

Assuming $p=p_{1}(r)+(N-z)^{2} p_{2}(r)$, inspection gives:

$$
\begin{gathered}
p_{2}=\text { constant } \\
\left.p_{1}=\int\left\{\frac{-1}{r}\left(\frac{f f^{\prime}}{r}-\frac{f^{2}}{r^{2}}\right)-\frac{1}{r R e}\left(D^{2}-M^{2}\right) f\right\} d r\right\}
\end{gathered}
$$

\subsection{Skin Friction}

The wall shear stress $\left(\tau_{r z}\right)$ of the pipe is known by:

$$
\tau_{r z}=\mu\left(\frac{\partial W}{\partial R}+\frac{\partial U}{\partial R}\right)=\frac{\mu}{a v_{0}} \frac{(N-z)}{r} D^{2} f
$$

Thus the skin-friction coefficient $C_{f}=\frac{2 \tau_{r z}}{\rho v_{0}^{2}}$ on $r=1$ is given by:

$$
C_{f}=\frac{2(N-z)}{R e} D^{2} f
$$

\subsection{Nusselt number}

The wall thermal flux (or heat flux) is known by:

$$
q_{w}=-\left.k_{T} \frac{\partial T}{\partial R}\right|_{(R=1)}
$$

The dimensionless heat transfer rate may be couched by:

$$
N u=\frac{a q_{w}}{k_{T} T_{1}}
$$

From Eq. (20) and Eq. (21), the Nusselt number $(\mathrm{Nu})$ obtained in the form:

$$
N u=-\left.\frac{\partial \theta}{\partial r}\right|_{(r=1)}=\text { constant }
$$

\section{HOMOTOPY SOLUTION}

The initial approximations of the velocity $f(r)$ and temperature $\theta(r)$ are chosen for HAM solutions as:

$$
f_{0}=r^{2}\left(2-r^{2}\right) \text { and } \theta_{0}^{\prime}(r)=1
$$

with the auxiliary linear operators are: $L_{1}(f)=D^{4}$ and $L_{2}(\theta)=\nabla^{2}$. With

$$
\left.\begin{array}{c}
L_{1}\left[c_{1} r^{4}+c_{2} r^{2}(2 \log r-1)+c_{3} r^{2}+c_{4}\right] \\
L_{2}\left[(N-z)^{2}\left(c_{5}+c_{6} \log r\right)+c_{7} r^{2}+c_{8}(\log r-1)\right]
\end{array}\right\}
$$

Where $C_{i}\left(\mathrm{i}=1\right.$ to 8 ) are constants. $h_{1}$ and $h_{2}$ (the convergence control parameters) are introduced in zeroth-order deformations.

The zeroth-order deformations; non-linear operators $N_{1}$ and $N_{2}$ are considered as explained in the work of (Nagaraju et al., (2018); Nagaraju and Mahesh (2019)).

h-curves are plotted with $M=5, \operatorname{Re}=10, \operatorname{Pr}=0.7, E c=0.05, Q=0.5$, $N=2, z=0.75$ and $r=0.25$ for the optimal values of $h_{1}$ and $h_{2}$ and are shown in Figs. 2-3. The admissible values of $h_{1}$ and $h_{1}$ are noted as $h_{1}=h_{2}=-0.1$.

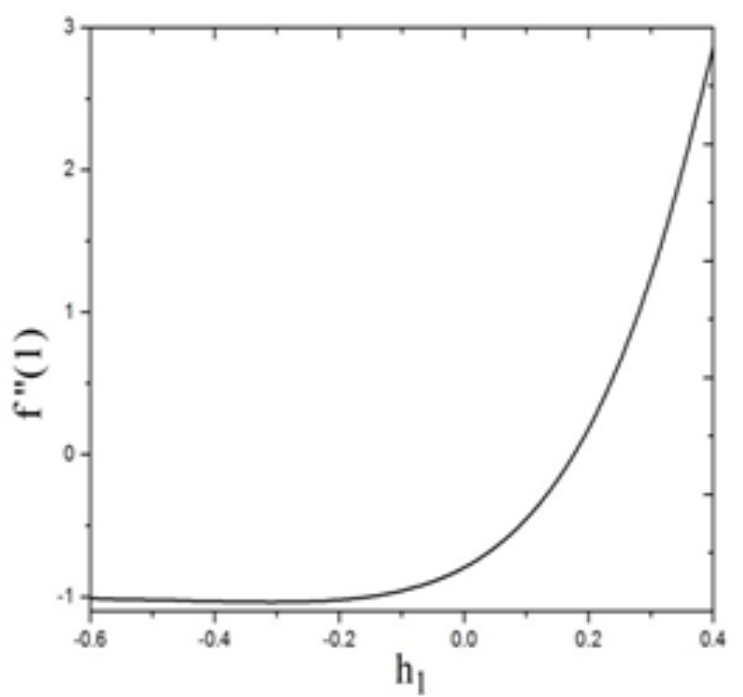

Fig. $2 \mathrm{~h}$ curve for $f(r)$

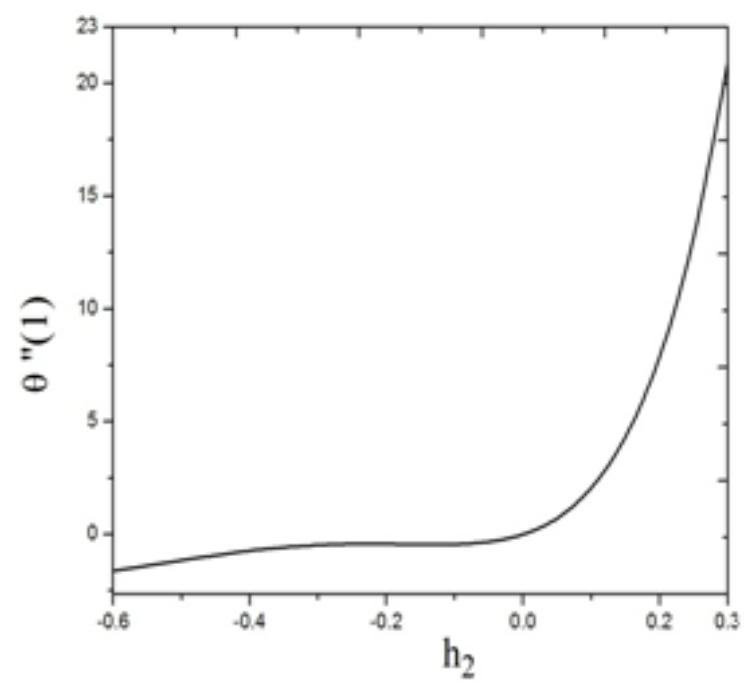

Fig. 3 h curve for $\theta(r)$

\section{RESULTS AND DISCUSSION}

Figures 4-6 display the response of $M$ on $f, f^{\prime}$ and $\theta$. It can be observed from these figures that the radial velocity and temperature magnitudes are enhanced with an increase in the parameter $M$, where the axial velocity the maximum values of $f^{\prime}$ are reduced and shifted towards the origin (axis of the cylinder) with the increasing values of $M$. The radial acceleration and axial deceleration are due to the Lorentzian magnetic body forces. The radial component assists momentum development and enhances the flow in the $r$-direction. The axial Lorentzian magnetic force acts to inhibit flow especially at larger values of the radial coordinate. In Fig. 6 we observe that as magnetic parameter increases, the temperature also increases. The presence of magnetic field implies that greater work must be expended to drag the fluid against the action of the inhibiting field (axial flow). The present energy is dissipated as heat and this demonstrations to hoist temperatures in Newtonian liquid. 


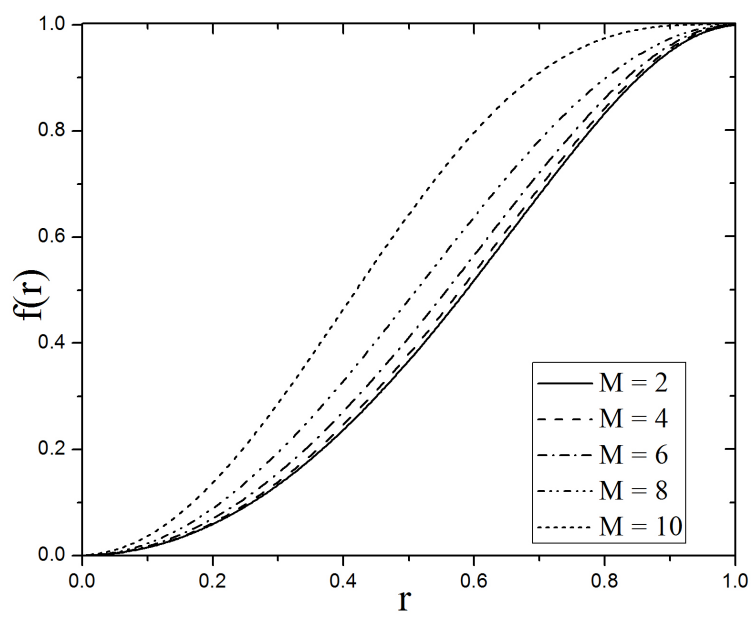

Fig. 4 Response of $M$ on $f$

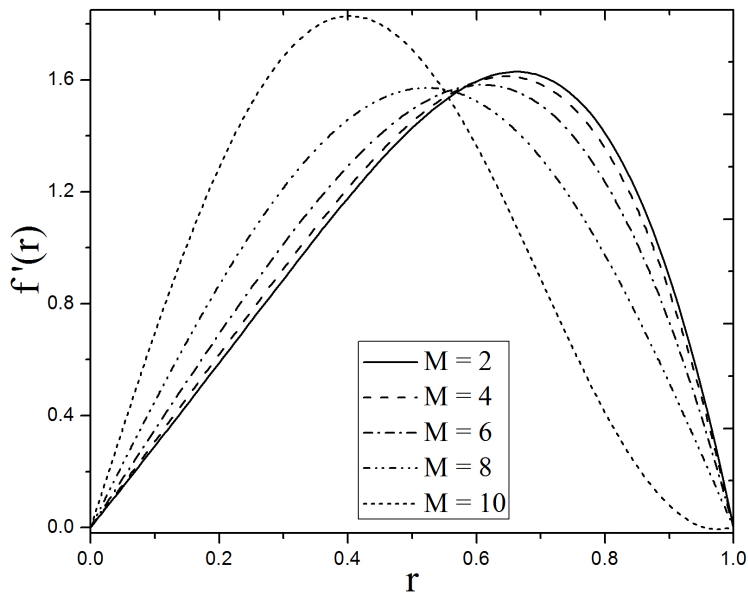

Fig. 5 Response of $M$ on $f$,

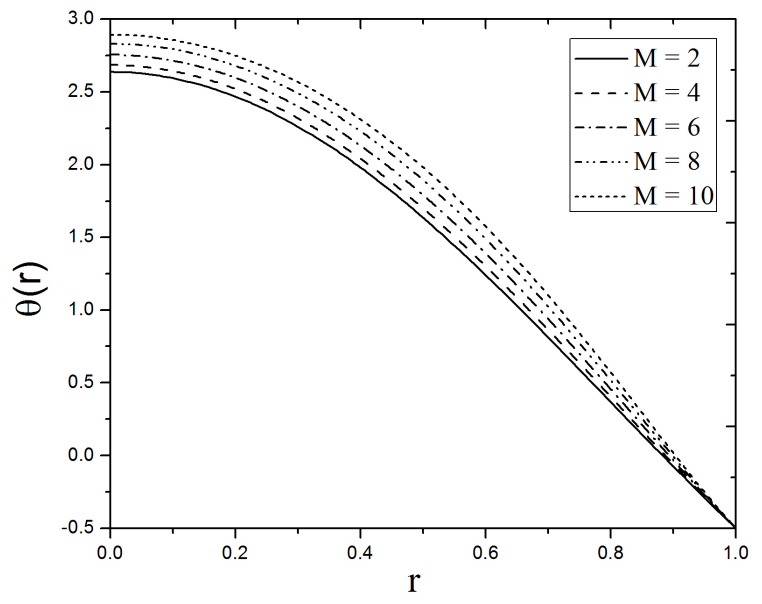

Fig. 6 Response of $M$ on $\theta$

From Fig. 7, clearly the velocity of the $r$-direction increases as $R e$ increases. From Fig. 8, we notice that while $R e$ increases, the maximum values of $f^{\prime}$ are reduced. This finding is opposite to the response of $M$ which enhances the maximum values of $f^{\prime}$. This may occur despite the fact that greater $R e$ implies a greater inertial force in the regime relative to viscous force, thereby decelerating the radial flow. Re can not induce a force in perpendicular direction as in the case of magnetic number. It is also evident from Fig. 9 that as the $R e$ increases, the temperature distribution decreases near axis of cylinder. This indicates that when Re increases, thermal diffusion in the laminar regime is inhibited.

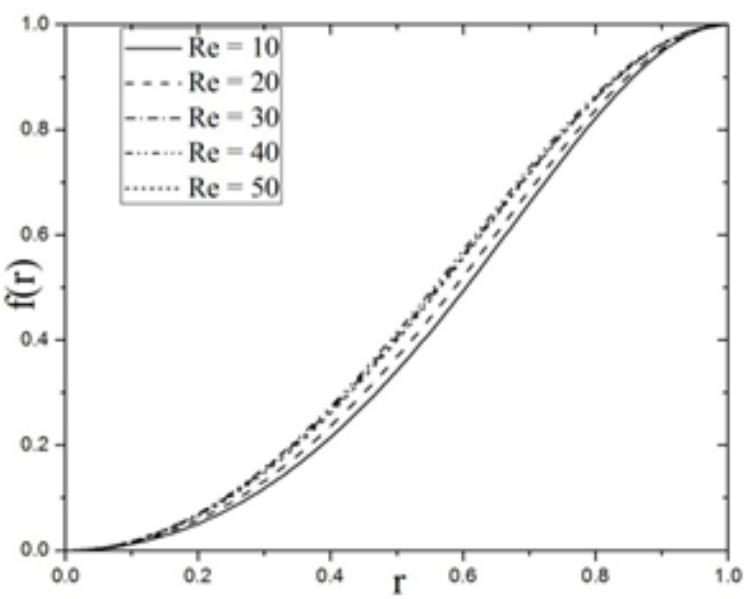

Fig. 7 Response of $\operatorname{Re}$ on $f$

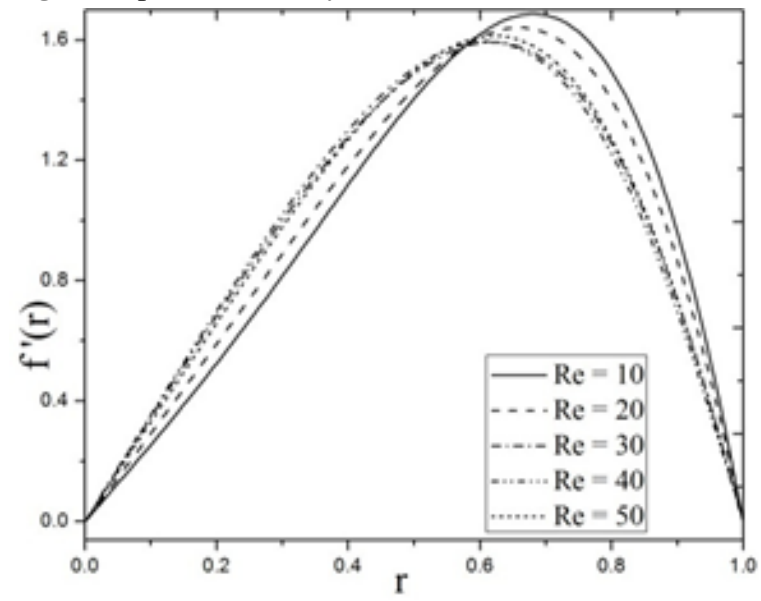

Fig. 8 Response of $\operatorname{Re}$ on $f$,

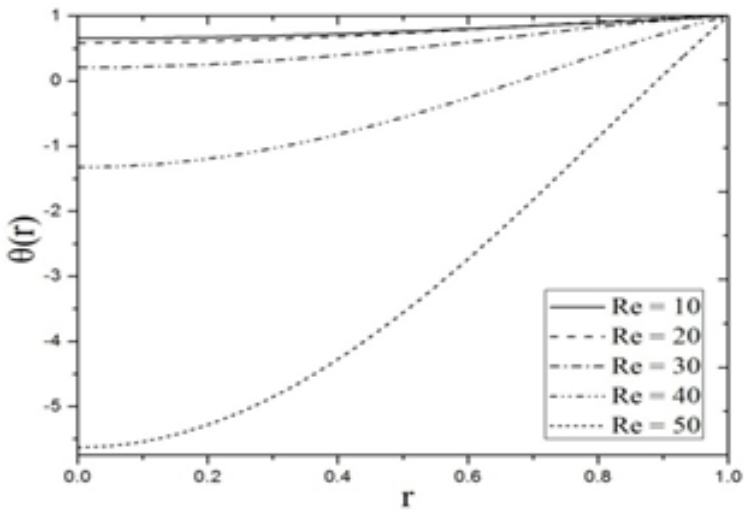

Fig. 9 Response of $\operatorname{Re}$ on $\theta$

From Fig. 10 and Fig. 11, we observe that when the Eckert number $(E c)$ increases the temperature near the axis of a pipe and as the number of Prandtl $(\mathrm{Pr})$ increases, $\theta$ increases. The conflicting behavior of $\operatorname{Pr}$ and $E c$ is well known in thermal transport. The impact of $Q$ on $\theta$ is shown in Fig. 12 at the point when evaluated that heat source gives an expansion in $\theta$, despite the fact that heat sink decelerates in temperature $(\theta)$. 


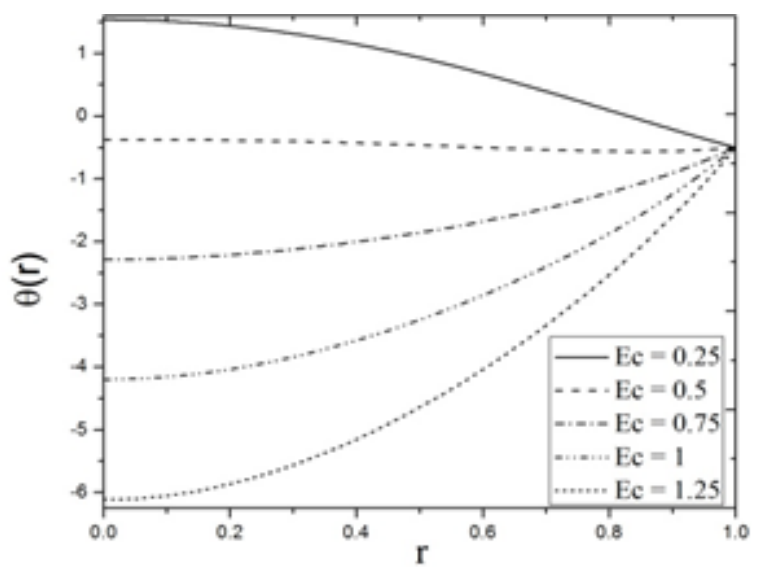

Fig. 10 Response of $E c$ on $\theta$

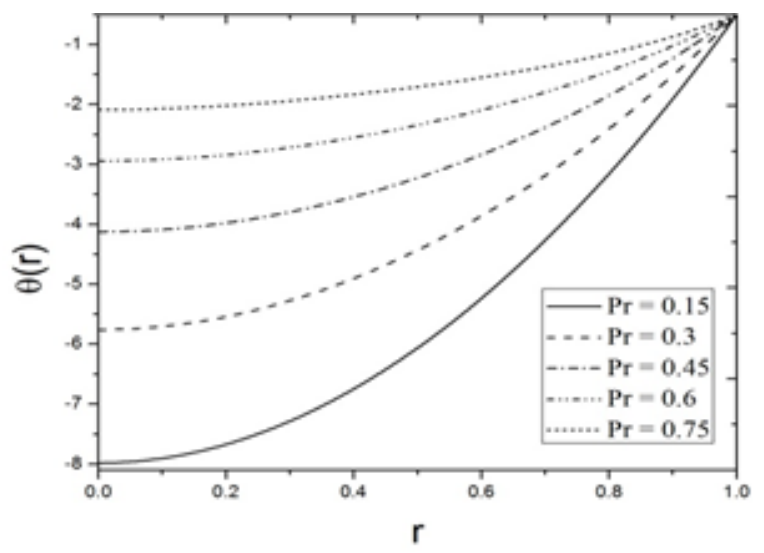

Fig. 11 Response of $\operatorname{Pr}$ on $\theta$

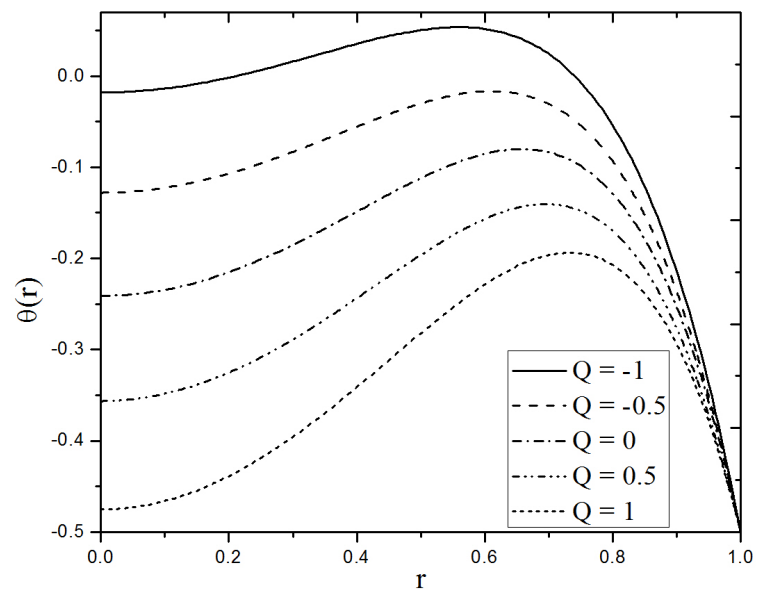

Fig. 12 Response of $Q$ on $\theta$

The Eq. (22) is identical to that considered in Srinivas et al., (2014) and Nagaraju et al., (2018). The solution comparison is documented in Table 2 excellent correlation is accomplished and therefore confidence in the current alternatives is reasonably high.
Table 1 Variation of Nusselt number for different values of various flow parameters.

\begin{tabular}{|c|c|c|c|c|c|c|c|}
\hline \multirow{2}{*}{$R e$} & \multirow{2}{*}{$Q$} & \multirow{2}{*}{$M$} & \multirow{2}{*}{$E c$} & \multicolumn{4}{|c|}{$N u$} \\
\hline & & & & $\begin{array}{l}P r= \\
0.15\end{array}=$ & $\begin{array}{l}P r= \\
0.3\end{array}$ & $\begin{array}{l}P r \\
0.45\end{array}=$ & $\begin{array}{l}P r= \\
0.6\end{array}$ \\
\hline 2 & \multirow{4}{*}{-0.5} & \multirow{4}{*}{3} & \multirow{4}{*}{0.75} & 9.3001 & 9.33229 & 9.36449 & 9.39668 \\
\hline 4 & & & & 6.1585 & 6.07011 & 5.98171 & 5.89331 \\
\hline 6 & & & & 1.3988 & 0.931253 & 0.463653 & -0.00395 \\
\hline 8 & & & & -5.4808 & -6.71935 & -7.95793 & -9.19651 \\
\hline \multirow{4}{*}{3} & \multirow{4}{*}{-0.5} & \multirow{4}{*}{3} & 0.2 & 0.9126 & -0.57783 & -2.42565 & -4.68941 \\
\hline & & & 0.4 & 4.2547 & 3.03265 & 1.4799 & -0.45998 \\
\hline & & & 0.6 & 7.5968 & 6.64313 & 5.38545 & 3.76944 \\
\hline & & & 0.8 & 10.9388 & 10.2536 & 9.291 & 7.99887 \\
\hline \multirow{4}{*}{3} & \multirow{4}{*}{-0.5} & 2 & & 10.0251 & 9.27069 & 8.23334 & 6.86049 \\
\hline & & 4 & 0 75 & 10.2318 & 9.48261 & 8.44786 & 7.07462 \\
\hline & & 6 & 0.15 & 10.7348 & 9.99673 & 8.96841 & 7.59626 \\
\hline & & 8 & & 11.8436 & 11.1269 & 10.1125 & 8.74594 \\
\hline \multirow{4}{*}{3} & -1.5 & \multirow{4}{*}{3} & \multirow{4}{*}{0.75} & 10.0906 & 9.33353 & 8.30318 & 6.94999 \\
\hline & -0.5 & & & 10.1033 & 9.35099 & 8.31461 & 6.94151 \\
\hline & 0.5 & & & 10.1161 & 9.36849 & 8.32606 & 6.93286 \\
\hline & 1.5 & & & 10.1289 & 9.38605 & 8.33752 & 6.92402 \\
\hline
\end{tabular}

Table 2 Comparison of Nusselt number for various values of $P r$ with $R e$ $=10, M=0.25, E c=0.3, Q=0$

\begin{tabular}{|c|c|c|c|}
\hline \multirow{2}{*}{$P r$} & \multicolumn{3}{|c|}{$N u$} \\
\cline { 2 - 4 } & Nagaraju et al., (2018) & Srinivas et al., (2014) & Present \\
\hline 0.15 & -1.7123 & -1.7093 & -1.72282 \\
\hline 0.3 & -11.5664 & -11.5694 & -11.5868 \\
\hline 0.45 & -28.9654 & -29.0964 & -29.2861 \\
\hline 0.6 & -57.8920 & -58.4890 & -58.74 \\
\hline
\end{tabular}

It is evident from Fig. 13 that streamlines are non-positive for $z>$ $N$ and positive for $z \leq N$. Numerically, the streamlines for the $z=N$ line are symmetrical. The streamlines are more clustered for lower $z$ values and more dispersed for greater $z$ values indicating that the intensity of the flow is greater at lower $z$ (axial coordinate).

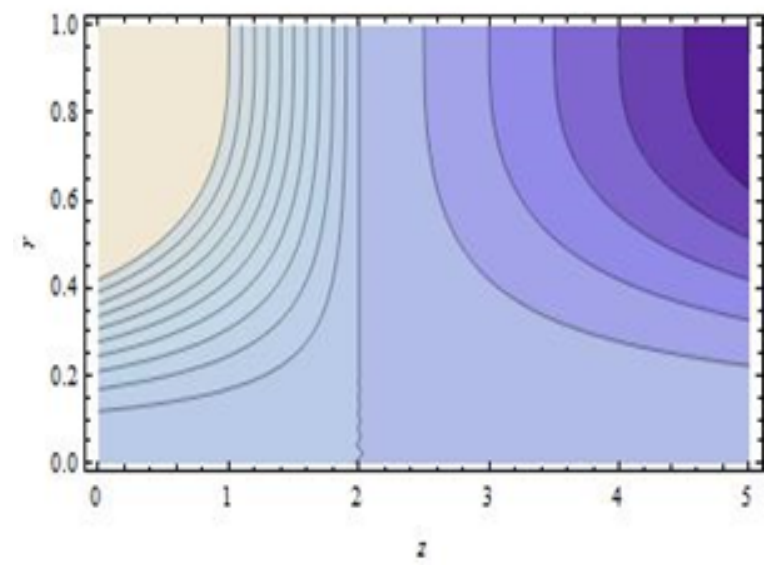

Fig. 13 Velocity Stream lines:

It is noted from Fig. 14 that the distribution of temperature is symmetrical about the line $z=N$. The temperature is nearest to the cylinder surface (white coloring is available in this locale). The highest temperature has to be at $z=N, r=1$. Extents of temperature are brought down 
for higher estimations of spiral arrange $(r)$. Figure. 15 shows that the pressure on $z=N$ is symmetrical and decreases as range $r \geq 1 / 2$ and increases as $r<1 / 2$. Pressure increments to higher qualities close to the pipe birthplace as $z$ increments or diminish.

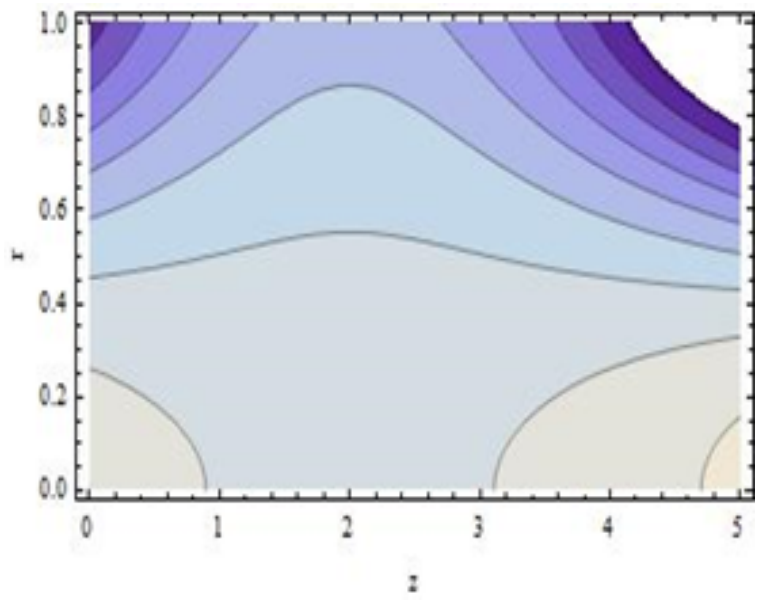

Fig. 14 Temperature Isotherms

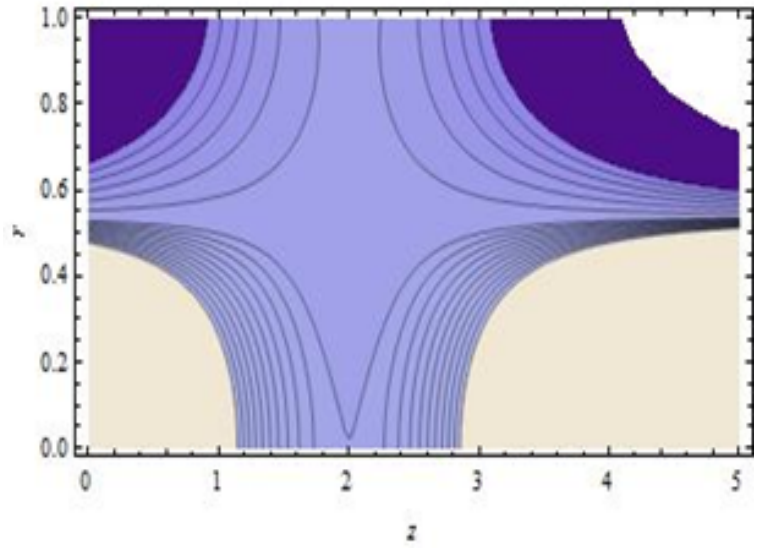

Fig. 15 Pressure contours

\section{CONCLUSIONS}

Analytical solutions are obtained in the viscous magnetohydrodynamic pipe flow for heat transfer using the HAM method. Viscous heating, injection/absorption of walls and internal heat source/sink effects have been incorporated in the energy equation. The observations from the figures show that:

(i) Increasing magnetic body force parameter accelerates the radial flow, whereas it tends to decelerate axial flow. This means that external magnetic force decelerates the flow in axial direction and enhances the flow in radial direction.

(ii) As magnetic Parameter $M$ increases velocity in axial direction increases and hence dissipation of energy increases and this causes raise in temperature.

(iii) Increase suction Reynolds number slow down axial velocity and enhances the radial velocity. This may be due to conservation of mass law, because in flow and out flow are to be balanced.

(iv) As the Eckert number or Prandtl number increases, the temperature on the axis of the pipe decreases. (v) As $Q$ increases temperature on the axis of the tube numerically increases. When $Q$ is fixed the temperature increases in the radial direction and suddenly decreases near the surface of the tube.

\section{ACKNOWLEDGEMENTS}

The Authors wish to thank the reviewers for their positive comments which improved the quality of the paper.

\section{NOMENCLATURE}

$\begin{array}{ll}W, U & \text { velocity components in }(\mathrm{Z}, \mathrm{R}) \text { directions }(\mathrm{m} / \mathrm{s}) \\ w, u & \text { Dimensionless axial and radial velocity coefficients } \\ P, p & \text { Dimensional and dimensionless presure }(\mathrm{Pa}) \\ c_{p} & \text { specific heat at constant pressure }(\mathrm{J} / \mathrm{kg} \cdot \mathrm{K}) \\ \rho & \text { density }\left(\mathrm{kg} / \mathrm{m}^{3}\right) \\ \mu & \text { Viscosity }\left(\mathrm{m}^{2} / \mathrm{s}\right) \\ \sigma & \text { specific conductance }\left(\mathrm{W} / \mathrm{m}^{2} \cdot \mathrm{K}^{4}\right) \\ k_{T} & \text { thermal conductivity }(\mathrm{W} / \mathrm{m} \cdot \mathrm{K}) \\ Q_{0} & \text { heat source/sink }(\mathrm{j}) \\ T_{1} & \text { temperature at surface }(\mathrm{K}) \\ \pi & \text { dissipation function } \\ v_{0} & \text { Suction velocity } \\ R e & \text { suction Reynolds number } \\ M & \text { Magnetic parameter } \\ P r & \text { Prandtl number } \\ E c & \text { Eckert number (viscous heating parameter }) \\ Q & \text { Heat source/sink parameter } \\ E^{2} & \text { stoke's stream function operator } \\ N=U_{0} / v_{0} & \text { entrance velocity } \\ U_{0} & \text { Laplacian operator } \\ \nabla^{2} & \text { uniform wall heat flux per unit area }\left(\mathrm{W} / \mathrm{m}^{2}\right) \\ q_{w} & \end{array}$

\section{REFERENCES}

Ahmet, Z.Sahin., Rached, Ben-Mansour., 2003, " Entropy Generation in Laminar Fluid Flow Through a Circular Pipe," Entropy, 5, 404-416. https://doi.org/10.3390/e5050404

Amanulla, Ch., Nagendra, N., Suryanarayana Reddy, M., 2018, "Numerical Simulation of Slip Influence on Electric Conducting Viscoelastic Fluid Past an Isothermal Cylinder," Frontiers in Heat and Mass Transfer, 10, 1-13.

https://doi.10.5098/hmt.10.10

Anwar Beg, O., Takhar, H.S., Tasveer, A. Beg., Bhargava, R., Rawat, S., 2008, "Nonlinear Magneto-Heat Transfer in a Fluid Particle Suspension Flowing in a Non-Darcian Channel with Heat Source and Buoyancy Effects: Numerical Study," JKAU: Engineering Science, 19(1), 63-89. https://doi.10.4197/Eng.19-1.4

Anwar Beg, O., Zueco, J., Takhar, H.S., 2009, "Unsteady Magnetohydrodynamic Hartmann Couette Flow and Heat Transfer in a Darcian Channel with Hall Current, Ionslip, Viscous and Joule Heating Effects: Network Numerical Solutions," Communications in Nonlinear Science and Numerical Simulation ,14, 1082-1097.

https://doi.org/10.1016/j.cnsns.2008.03.015

Anwar Beg, O., Ghosh, S.K., Beg, T.A., 2011, "Applied Magnetofluid Dynamics: Modelling and Computation," Lambert, Germany, 445. ISBN 10: 3846508659/ ISBN 13: 9783846508657

Attia, H.A., 2003, "Unsteady Flow of a Dusty Conducting NonNewtonian Fluid Through a Pipe," Candian Journal of Physics, 81, 789795.

https://doi.org/10.1139/p03-054 
Aydin, O., 2005, "Effects of Viscous Dissipation on the Heat Transfer in Forced Pipe Flow. Part 1: Both Hydrodynamically and Thermally Fully Developed Flow," Energy Conversion and Management, 46, 757-769. https://doi.org/10.1016/j.enconman.2004.05.004

Bansal, J.L., 1967, "Laminar Flow Through a Uniform Circular Pipe with Small Suction," Proc. Natn. Acad. Sci., 32A(4), 368-378.

Berman, A.S.,1953, "Laminar Flow in Channels with Porous Walls," Journal of Applied Physics, 24, 1232-1235.

https://doi.org/10.1063/1.1721476

Bird, R.B., Stewart, W.E., Lightfoot, E.N., 1960, "Transport Phenomena," John Wiley and Sons, New York.

Brinkman,H.C.,1951, "Heat Effects in Capillary Flow," Applied Scientific Research, A2 , 120-124.

https://doi.org/10.1007/BF00411976

Cox, B.J., Hill, J.M., 2011, "Flow Through a Circular Tube with Permeable Navier Slip Boundary," Nanoscale Research Letters. 6, 1-9. https://doi.org/10.1186/1556-276X-6-389

Davaa, G., Shigechi, T., Momoki, S., 2004, "Effect of Viscous Dissipation on Fully-Developed Heat Transfer of Non-Newtonian Fluids in Plane Laminar Poiseuille-Couetteflow," International Journal of Heat and Mass Transfer31, 663-672.

https://doi.org/10.1016/S0735-1933(04)00053-3

Gebhart, B., 1962, "Effects of Viscous Dissipation in Natural Convection," Journal of Fluid Mechanics, 14, 225-232.

https://doi.org/10.1017/S0022112062001196

Hazem, A. Attia., Mohamed, Ahmed, E.S., 2005, "Circular Pipe MHD Flow of a Dusty Bingham Fluid," Tamkang Journal of Science and Engineering, 8(4), 257-265.

http://www2.tku.edu.tw/ tkjse/8-4/8-4-1.pdf

Hussein, H.M.S., Mohamad, M.A., El-Asfouri, A.S., 1999, "Optimization of a Wickless Heat Pipe Flat Plate Solar Collector," Energy Conversion and Management, 40, 1949-1961.

https://doi.org/10.1016/S0196-8904(99)00082-5

Leonard L.Vasilev, 2005, "Heat Pipes in Modern Heat Exchangers," Applied Thermal Engineering, 25, 1-19.

https://doi.org/10.1016/j.applthermaleng.2003.12.004

Liao, S.J., 2003, "Beyond Perturbation: Introduction to Homotopy Analysis Method," Chapman and Hall/CRC Press, Boca Raton. https://www.crcpress.com/Beyond-Perturbation-Introduction-to-theHomotopy-Analysis-ethod/Liao/p/book/9781584884071

Moustafa, EL-Shahed., 2006, "MHD of a Fractional Viscoelastic Fluid in a Circular Tube," Mechanics Research Communication, 33, 261-268. https://doi.org/10.1016/j.mechrescom.2005.02.017

Nabil, T. El Dabe., Galal, M.Moatimid., Hoda, S.M. Ali., 2002, "RivlinEriksen Fluid in Tube of Varying Cross Section with Mass and Heat Transfer," Zeitschrift fur Naturforschung A, 57 a, 863-873.

https://doi.org/10.1515/zna-2002-1105

Nagaraju, G., Anjanna, Matta., Kaladhar, K., 2016, "Effects of Chemical Reaction and Thermal Radiation on Heat Generated Stretching Sheet in a Couple Stress Fluid Flow," Frontiers in Heat and Mass Transfer, 7(11), 1-5.

https://doi.org/10.5098/hmt.7.11
Nagaraju, G., Srinivas, J., Ramana Murthy, J.V., Rashad, A.M., 2017, "Entropy Generation Analysis of the MHD Flow of Couple Stress Fluid Between Two Concentric Rotating Cylinders with Porous Lining," Heat Transfer-Asian Research, 46(4), 316-330.

https://doi.org/10.1002/htj.21214

Nagaraju, G., Srinivas Jangili., Ramana Murthy, J.V., Beg, O.A., Kadir, A., 2018, "Second Law Analysis of Flow in a Circular Pipe with Uniform Suction and Magnetic Field," Journal of Heat transfer, 141(1) http//doi.10.1115/1.4041796.

Nagaraju, G., Mahesh Garvandha, 2019, "Magnetohydrodynamic Viscous Fluid Flow and Heat Transfer in a Circular Pipe Under an Externally Applied Constant Suction," Heliyon, 5, (2019)e01281.

http//doi.10.1016/j.heliyon.2019.e01281.

Ou, J.W., Cheng, K.C., 1973, "Viscous Dissipation Effects on Thermal Entrance Heat Transfer in Pipe Flows with Uniform Wall Heat Flux," Applied Scientific Research, 28, 289-301.

https://doi.org/10.1007/BF00413074

Rached, Ben-Mansour., Ahmet, Z.Sahin., 2005, "Entropy Generation in Developing Laminar Fluid Flow Through a Circular Pipe with Variable Properties," Heat and Mass Transfer, 42, 1-11.

https://doi.org/10.1007/s00231-005-0637-6

RamanaMurthy, J.V., Nagaraju, G., Muthu, P., 2012, "Micropolar Fluid Flow Generated by a Circular Cylinder Subject to Longitudinal and Torsional Oscillations with Suction/Injection," Tamkang Journal of Mathematics, 43(3), 339-356.

https://doi.10.5556/j.tkjm.43.2012.339-356

Rhee, K.N., Yeo, M.S., Kim, K.W., 2011, "Evaluation of the Control Performance of Hydronic Radiant Heating Systems Based on the Emulation Using Hardware in the Loop," Building and Environment, 46, 2012 - 2022.

https://doi.org/10.1016/j.buildenv.2011.04.012

Srinivas, S., Subramanyam Reddy, A., Ramamohan, T.R., Anant Kant Shukla., 2014, "Influence of Heat Transfer on MHD Flow in a Pipe with Expanding or Contracting Permeable Wall," Ain Shams Engineering Journal, 5, 817 - 830.

https://doi.org/10.1016/j.asej.2014.01.006

Terril, R.M., Shrestha, G.M., 1963, "Laminar Flow Through Channels With Porous Walls and with an Applied Transverse Magnetic Field," Applied Scientific Research, 11, 134-144. https://doi.org/10.1007/BF02922219

Terril, R.M., 1982, "An Exact Solution for Flow in a Porous Pipe," ZAMP, 33, 547-542.

https://doi.org/10.1007/BF00955703

Terril,R.M., 1983, "Laminar Flow Through a Porous Tube," ASME Journal of Fluids Engineering, 105, 303-306.

https://doi.10.1115/1.3240992

Tien, C.L., 1975, "Fluid Mechanics of Heat Pipes," Annual Review of Fluid Mechanics, 7, 167-185.

https://doi.org/10.1146/annurev.fl.07.010175.001123 
Tsangaris, S., Kondaxakis, D., 2007, "Exact Solution for Flow in a Porous Pipe with Unsteady Wall Suction/Injection," Communications in Nonlinear Science and Numerical Simulations, 12, 1181-1189.

https://doi.org/10.1016/j.cnsns.2005.12.009
Walker, K.L., Tarau, C., Anderson, W.G., 2013, " Grooved and SelfVenting Arterial Heat Pipes for Space Fission Power Systems," 17th International Heat Pipe Conference, October, 13-17. https://doi.10.1615/HeatPipeScieTech.v5.i1-4.580 